\title{
PENGARUH PENGGUNAAN TEKNOLOGI INFORMASI \\ DAN MINAT PEMANFAATAN TEKNOLOGI INFORMASI TERHADAP KINERJA PEGAWAI DI BKKBN KABUPATEN MADIUN
}

\author{
Tuti Hariyani \\ Magister Akuntansi Universitas Sebelas Maret \\ bagindaeka@gmail.com
}

\begin{abstract}
ABSTRAK
Agar teknologi informasi dapat meningkatkan kinerja organisasi atau institusi yang melakukan investasi, teknologi ini harus dapat diterima dan digunakan terlebih dahulu oleh pemakai-'pemakainya sehingga besarnya dana yang dipakai dalam melakukan investasi atas teknologi informasi, akan diimbangi dengan kinerja individual anggota organisasi atau institusinya. Metode penelitian yang digunakan adalah explanative research. Populasi penelitian adalah pegawai BKKBN Kabupaten Madiun yang berjumlah 32 orang. Teknik sampling adalah purposive sampling dan menggunakan alat uji statistik Regresi Linier, dengan variabel independen Penggunaan Teknologi Informasi dan Minat Pemanfaatan Teknologi Informasi, serta variabel dependen Kinerja Pegawai BKKBN. Hasil dari penelitian ini adalah dari 32 responden diketahui bahwa nilai t hitung variabel Penggunaan Teknologi Informasi adalah 1,880 dengan tingkat signifikansi sebesar 0,039., hal ini disimpulkan bahwa terdapat pengaruh secara parsial variabel Penggunaan Teknologi Informasi terhadap variabel terikat Kinerja Pegawai BKKBN, nilai t hitung variabel Minat Pemanfaatan Teknologi Informasi adalah 2,922 dengan tingkat signifikansi sebesar 0,007, hal ini disimpulkan bahwa terdapat pengaruh yang signifikan antara variabel bebas Minat Pemanfaatan Teknologi Informasi terhadap variabel terikat Kinerja Pegawai BKKBN Kabupaten Madiun.

Berdasarkan hasil penelitian, dapat disimpulkan bahwa terdapat pengaruh antara Penggunaan Teknologi Informasi dan Minat Pemanfaatan Teknologi Informasi terhadap Kinerja Pegawai BKKBN Kabupaten Madiun
\end{abstract}

Kata kunci: Penggunaan Teknologi Informasi, Minat Pemanfaatan Teknologi Informasi, Kinerja

\section{PENDAHULUAN}

Teknologi informasi khususnya teknologi komputer sangat berpotensi untuk memperbaiki performa individu dan organisasi, karenanya banyak pengambil keputusan menginvestasikan dana untuk teknologi informasi. Menurut Sungmin Kang (1998), teknologi informasi akan membantu perusahaan untuk memperbaiki performance organisasi, hanya apabila perusahaan menggunakan teknologi informasi secara aktual dalam langkah yang efisien, sehingga penerapan teknologi baru dalam suatu organisasi akan berpengaruh pada keseluruhan organisasi, terutama pada sumber daya manusia.

Agar teknologi informasi dapat meningkatkan kinerja organisasi atau institusi yang melakukan investasi, teknologi ini harus dapat diterima dan 
digunakan terlebih dahulu oleh pemakai-'pemakainya sehingga besarnya dana yang dipakai dalam melakukan investasi atas teknologi informasi, akan diimbangi dengan kinerja individual anggota organisasi atau institusinya secara signifikan. Menurut Lucas dan Spitler (1999), agar teknologi informasi dapat diterapkan secara efektif sehingga dapat memberikan kontribusi terhadap kinerja maka anggota dalam organisasi harus dapat menggunakan teknologi tersebut dengan baik dan memberikan kontribusi terhadap kinerjanya. Sedangkan menurut Goodhue dan Thomson (1995), agar suatu teknologi informasi memberikan dampak yang positif terhadap kinerja individual maka teknologi tersebut harus dimanfaatkan dengan tepat dan harus mempunyai kecocokan dengan tugas yang dilakukannya.

\section{TINJAUAN PUSTAKA}

Menurut McKeown (2001) yang dimaksud dengan teknologi informasi adalah "teknologi informasi merujuk pada seluruh bentuk teknologi yang digunakan untuk menciptakan, menyimpan, mengubah dan menggunakan informasi dalam segala bentuknya." Dalam Kamus Oxford (Kadir, 2003), teknologi informasi didefinisikan sebagai studi atau penggunaan peralatan elektronika, terutama komputer untuk menyimpan, menganalisa dan mendistribusikun informasi apa saja, termasuk kata-kata, bilangan dan gambar. Secara umum Lucas (2000) menyatakan bahwa teknologi informasi adalah segala bentuk teknologi yang diterapkan untuk memproses dan mengirimkan informasi dalam bentuk elektronis. Menurut Senn (2004), teknologi informasi didefinisikan sebigai sebuah istilah yang merujuk ke hal-hal dan keahlian yang digunakan daiam ponciptaan, penyimpanan, penyebaran

Dalam model teknologi informasi, O'Brain (2008) menyebutkan bahwa teknologi informasi bergantung pada sumber daya manusia, perangkat keras (hardware), perangkat lunak (software), data (data dan pengetahuan dasar) serta jaringan (media komunikasi dan dukungaI jaringan). Teknologi Informasi meliputi teknologi komputer (computing technology) dan teknologi komunikasi (communication technology) yang digunakan untukt memproses dan menyebarkan informasi baik yang bersifat finansial atau nonfinansial. Teknologi informasi dalam perusahaan berfungsi sebagai alat bantu pencapaian tujuan melalui penyediaan informasi. Kesuksesan teknologi informasi dapat diukur dengan empat jenis ukuran yaitii kepuasan pemakai, penggunaan sistem, kinerja keputusan, dan kinerja organisasi.

Minat seseorang terhadap suatu objek akan lebih kelihatan apabila objek tersebut sesuai sasaran dan berkaitan dengan keinginan dan kebutuhan seseorang yang bersangkutan (Sardiman, 1990). Menurut Tampubolon (1991) mengatakan bahwa minat adalah suatu perpaduan keinginan dan kemauan yang dapat berkembang jika ada motivasi. Sedangkan menurut Djali (2008) bahwa minat pada dasarnya merupakan penerimaan akan sesuatu hubungan antara diri sendiri dengan sesuatu di luar diri. Menurut Thompson et.al. (2001), pemanfaatan teknologi informasi merupakan hal yang diharapkan oleh pengguna sistem informasi dalam melaksanakan tugasnya, dimana pengukurannya berdasarkan intensitas pemanfaatan, frekuensi pemanfaatan dan jumlah aplikasi atau perangkat lunak yang digunakan. 
Pemanfaatan teknologi juga berhubungan dengan perilaku menggunakan teknologi tersebut daiam menyelesaikan tugas. Theory of Reasoned Action (TRA) adalah suatu teori yang berhubungan dengai sikap dan perilaku individu daiam melaksanakan kegiatan. Seseorang akan memanfaatkan teknologi informasi dengan alasan bahwa teknologi tersebut akan menghasilkan manfaat bagi dirinya. Sheppard et al. (1988) menyatakan bahwa TRA telah digunakan untuk memprediksi suatu perilaku dalam banyak hal.

\section{METODE PENELITIAN}

Rancangan penelitian ini merupakan tipe penelitian penjelasan (explanatif research) dengan melakukan pengamatan/non-eksperimen karena menjelaskan hubungan kausal antara variabel-variabel melalui pengujian hipotesis tanpa memberikan perlakuan (Singarimbun, 2006) serta dengan sampel yang diambil dari suatu populasi dan menggunakan kuesioner sebagai alat pengumpul data yang pokok dan pada umumnya merupakan unit analisa individu.

Dalam penelitian ini yang digunakan sebagai sampel adalah Pegawai BKKBN Kabupaten Madiun yang berjumlah 32 orang.

\section{ANALISIS DAN PEMBAHASAN}

\section{Analisis}

a. Uji validitas

Pengujian instrumen dilakukan terlebih dahulu sebelum pengujian hipotesis. Pengujian ini menggunakan Pearson Correlation. Item yang valid mempunyai nilai koefisien korelasi $r_{\text {hitung }}$ lebih dari $(\geq) r_{\text {kritis }} 0.30$.

1) Uji validitas variabel Penggunaan Teknologi Informasi

Uji coba kuesioner variabel Penggunaan Teknologi Informasi dilakukan pada 15 orang responden yang terdiri dari pegawai BKKBN Kabupaten Madiun. Dari data scoring setelah dilakukan uji indeks diskriminasi item kuesioner Penggunaan Teknologi Informasi dengan komputasi Software SPSS 16.0 for windows untuk 12 item, 12 item dinyatakan valid.

Tabel 1 Validitas Kuesioner Penggunaan Teknologi Informasi

\begin{tabular}{|l|c|c|c|c|}
\hline No. & Item & Koefisien & Signifikan & Kriteria \\
\hline 1. & 1 & 0.788 & 0,000 & Valid \\
\hline 2. & 2 & 0.750 & 0.001 & Valid \\
\hline 3. & 3 & 0.779 & 0.001 & Valid \\
\hline 4. & 4 & 0.801 & 0.000 & Valid \\
\hline 5. & 5 & 0.824 & 0.000 & Valid \\
\hline 6. & 6 & 0.759 & 0.001 & Valid \\
\hline 7. & 7 & 0.864 & 0.000 & Valid \\
\hline 8. & 8 & 0.628 & 0.012 & Valid \\
\hline 9. & 9 & 0.771 & 0.001 & Valid \\
\hline 10. & 10 & 0.686 & 0.005 & Valid \\
\hline 11. & 11 & 0.658 & 0.008 & Valid \\
\hline 12. & 12 & 0.815 & 0.000 & Valid \\
\hline
\end{tabular}


2) Uji validitas variabel Minat Pemanfaatan Teknologi Informasi Uji coba kuesioner variabel Minat Pemanfaatan Teknologi Informasi dilakukan pada 15 orang responden yang terdiri dari pegawai BKKBN Kabupaten Madiun. Dari data scoring setelah dilakukan uji indeks diskriminasi item kuesioner Minat Pemanfaatan Teknologi Informasi dengan komputasi Software SPSS 16.0 for windows untuk 14 item, 14 item dinyatakan valid. Hasil penghitungan indeks diskriminasi item kuesioner Minat Pemanfaatan Teknologi Informasi dijelaskan pada tabel berikut:

Tabel 2 Validitas Kuesioner Minat Pemanfaatan Teknologi Informasi

\begin{tabular}{|l|c|c|c|c|}
\hline \multicolumn{1}{|c|}{ No. } & Item & Koefisien & Signifikan & Kriteria \\
\hline 1. & 1 & 0.908 & 0,000 & Valid \\
\hline 2. & 2 & 0.593 & 0.020 & Valid \\
\hline 3. & 3 & 0.731 & 0.002 & Valid \\
\hline 4. & 4 & 0.819 & 0.000 & Valid \\
\hline 5. & 5 & 0.771 & 0.001 & Valid \\
\hline 6. & 6 & 0.863 & 0.000 & Valid \\
\hline 7. & 7 & 0.684 & 0.005 & Valid \\
\hline 8. & 8 & 0.844 & 0.000 & Valid \\
\hline 9. & 9 & 0.660 & 0.007 & Valid \\
\hline 10. & 10 & 0.825 & 0.000 & Valid \\
\hline 11. & 11 & 0.671 & 0.006 & Valid \\
\hline 12. & 12 & 0.688 & 0.005 & Valid \\
\hline 13. & 13 & 0.790 & 0.000 & Valid \\
\hline 14. & 14 & 0.875 & 0.000 & Valid \\
\hline
\end{tabular}

3) Variabel Kinerja Pegawai

Uji coba kuesioner variabel Kinerja Pegawai dilakukan pada 15 orang responden. Dari data skoring setelah dilakukan uji indeks diskriminasi item kuesioner Kinerja Pegawai BKKBN Kabupaten Madiun dengan komputasi Software SPSS 16.0 for windows untuk 10 item, 10 item dinyatakan valid. Hasil penghitungan indeks diskriminasi item kuesioner Kinerja Pegawai dijelaskan pada tabel berikut:

Tabel 3 Validitas Kuesioner Kinerja Pegawai

\begin{tabular}{|l|c|c|c|c|}
\hline \multicolumn{1}{|c|}{ No. } & Item & Koefisien & Signifikan & Kriteria \\
\hline 1. & 1 & 0.730 & 0,002 & Valid \\
\hline 2. & 2 & 0.635 & 0.011 & Valid \\
\hline 3. & 3 & 0.566 & 0.028 & Valid \\
\hline 4. & 4 & 0.940 & 0.000 & Valid \\
\hline 5. & 5 & 0.934 & 0.000 & Valid \\
\hline 6. & 6 & 0.703 & 0.003 & Valid \\
\hline 7. & 7 & 0.701 & 0.004 & Valid \\
\hline 8. & 8 & 0.704 & 0.003 & Valid \\
\hline 9. & 9 & 0.957 & 0.000 & Valid \\
\hline 10. & 10 & 0.883 & 0.000 & Valid \\
\hline
\end{tabular}

\section{b. Uji Reliabilitas}

Pengukuran reliabilitas dengan menggunakan bantuan komputasi Software SPSS version 16.0 for windows. Program uji kehandalan dengan menggunakan 
teknik Alpha Cornbach dengan nilai reliabilitas Alpha Cornbach lebih besar $(\geq)$ dari $\mathrm{r}_{\text {kritis }} 0.700$.

1) Reliabilitas variabel Penggunaan Teknologi Informasi

Penghitungan reliabilitas kuesioner variabel Penggunaan Teknologi Informasi dilakukan pada 12 item yang valid, dengan nilai reliabilitas Alpha Cornbach 0.790 , yang berarti lebih besar $(\geq)$ dari $\mathrm{r}_{\text {kritis }} 0.700$ sebagaimana tertera pada tabel berikut:

\section{Tabel $4 \quad$ Uji Reliabilitas Kuesioner Penggunaan Teknologi Informasi}

\begin{tabular}{|c|c|c|c|}
\hline N Item & Alpha & $\mathbf{r}_{\text {kritis }}$ & Kriteria \\
\hline 12 & 0.790 & 0.700 & Reliabel \\
\hline
\end{tabular}

2) Reliabilitas variabel Minat Pemanfaatan Teknologi Informasi

Penghitungan reliabilitas kuesioner variabel Minat Pemanfaatan Teknologi Informasi dilakukan pada 12 item yang valid, dengan nilai reliabilitas Alpha Cornbach 0.790 , yang berarti lebih besar $(\geq)$ dari $r_{\text {kritis }} 0.700$ sebagaimana tertera pada tabel berikut:

Tabel $5 \quad$ Uji Reliabilitas Kuesioner Minat Pemanfaatan Teknologi Informasi

\begin{tabular}{|c|c|c|c|}
\hline N Item & Alpha & $\mathbf{r}_{\text {kritis }}$ & Kriteria \\
\hline 12 & 0.790 & 0.700 & Reliabel \\
\hline
\end{tabular}

3) Reliabilitas variabel Kinerja Pegawai

Penghitungan reliabilitas kuesioner variabel hasil belajar dilakukan pada 10 item yang valid, dengan nilai reliabilitas Alpha Cornbach 0.801, yang berarti lebih besar $(\geq)$ dari $r_{\text {kritis }} 0.700$ sebagaimana tertera pada tabel berikut:

\section{Tabel 6 Uji Reliabilitas Kuesioner Kinerja}

\begin{tabular}{|c|c|c|c|}
\hline N Item & Alpha & $\mathbf{r}_{\text {kritis }}$ & Kriteria \\
\hline 10 & 0.801 & 0.700 & Reliabel \\
\hline
\end{tabular}

\section{c. Uji Normalitas}

Setelah dilakukan uji Kolmogrov-Smirnov melalui komputasi Software SPSS Version 16.0 for Windows didapat nilai Kolmogrov-Smirnov sebagaimana tabel berikut:

Tabel 7 Uji Normalitas Data

One-Sample Kolmogorov-Smirnov Test

\begin{tabular}{|ll|r|}
\hline & & \multicolumn{1}{|c|}{$\begin{array}{l}\text { Unstandardized } \\
\text { Predicted Value }\end{array}$} \\
\hline $\mathrm{N}$ & & 32 \\
Normal Parameters & & \\
& Mean & .7333333 \\
Most Extreme Differences & Std. Deviation & .07289378 \\
& Absolute & .207 \\
& Positive & .207 \\
& Negative & -.214 \\
Kolmogorov-Smirnov Z & & 1.480 \\
Asymp. Sig. (2-tailed) & .508 \\
\hline a. Test distribution is Normal. & \\
\hline
\end{tabular}




\begin{tabular}{|ll|r|}
\hline \multicolumn{2}{|c|}{ One-Sample Kolmogorov-Smirnov Test } \\
\hline \multicolumn{2}{|c|}{} & $\begin{array}{r}\text { Unstandardized } \\
\text { Predicted Value }\end{array}$ \\
\hline$N$ & Mean & 32 \\
Normal Parameters ${ }^{a}$ & Std. Deviation & .7333333 \\
& Absolute & .07289378 \\
Most Extreme Differences & Positive & .207 \\
& Negative & .207 \\
& & -.214 \\
Kolmogorov-Smirnov Z & & 1.480 \\
Asymp. Sig. (2-tailed) & & .508 \\
\hline & & \\
\end{tabular}

Berdasarkan tabel diatas, nilai K-S Z 1,480 dan $\mathrm{P}_{\text {hitung }} 0.508$ lebih besar dari $(\geq) \mathrm{P}_{\text {kritis }} 0.05$ maka dianggap normal).

\section{d. Uji Multikolinieritas}

Tabel 8 asil Uji Multikolinieritas

\begin{tabular}{|ll|c|c|}
\hline \multicolumn{1}{|c|}{ Variabel Bebas } & VIF & \multicolumn{1}{c|}{ Keterangan } \\
\hline 1. & $\begin{array}{l}\text { Penggunaan Teknologi } \\
\text { Informasi (X1) }\end{array}$ & 2,215 & Non Multikolinieritas \\
\hline 2. & $\begin{array}{l}\text { Minat Pemanfaatan Teknologi } \\
\text { Informasi(X2) }\end{array}$ & 2.215 & Non Multikolinieritas \\
\hline
\end{tabular}

Dari Tabel 8 tersebut dapat diketahui bahwa variabel bebas memiliki nilai VIF < 5,5 sehingga tidak terjadi multikolinieritas, dengan demikian layak digunakan sebagai analisis selanjutnya.

\section{e. Hasil Uji Heteroskedastisitas}

Hasil uji heteroskedatisitas dapat dilihat pada gambar 2 scatterplot berikut ini :

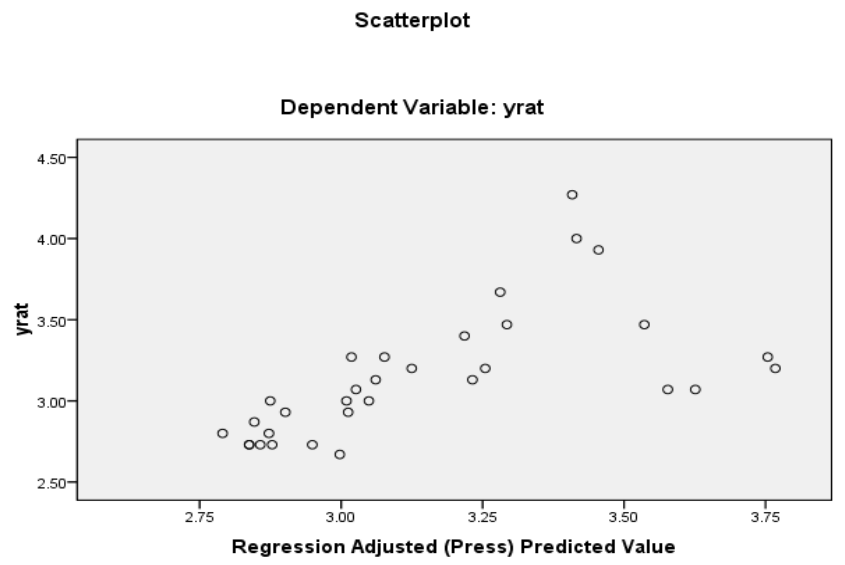

Gambar 1 Hasil Uji Heteroskedastisitas

Pada gambar scatterplot di atas, diketahui semua titik tidak membentuk pola tertentu. Hal ini menunjukkan tidak adanya heteroskedastisitas. 
f. Uji Hipotesis

1) Pengujian terhadap koefisien regresi variabel Penggunaan Teknologi Informasi, nilai t hitung adalah 1,880 dengan tingkat signifikansi sebesar 0,039. Dikarenakan nilai siqnifikasi t nya $<0,05$ maka diperoleh hasil pengujian bahwa bahwa menolak Ho dan menerima Hi. Hal ini disimpulkan bahwa "Terdapat pengaruh secara parsial antara variabel bebas Penggunaan Teknologi Informasi terhadap variabel terikat Kinerja Pegawai BKKBN Kabupaten Madiun (Y).”

2) Pengujian terhadap koefisien regresi variabel Minat Pemanfaatan Teknologi Informasi, nilai $\mathrm{t}$ hitung adalah 2,922 dengan tingkat signifikansi sebesar 0,007. Dikarenakan nilai siqnifikasi t-nya $<0,05$ maka diperoleh hasil pengujian bahwa maka diperoleh hasil pengujian bahwa bahwa menolak Ho dan menerima Hi. Hal ini disimpulkan bahwa "Terdapat pengaruh secara parsial antara variabel bebas Minat Pemanfaatan Teknologi Informasi terhadap variabel terikat Kinerja Pegawai BKKBN Kabupaten Madiun (Y).”

\section{PEMBAHASAN HASIL PENELITIAN}

Ditinjau dari hasil uji-t, yaitu uji secara parsial terbukti bahwa kedua variabel bebas dalam penelitian ini, yaitu: Penggunaan Teknologi Informasi dan Minat Pemanfaatan Teknologi Informasi berpengaruh signifikan secara parsial terhadap variabel terikat Kinerja Pegawai BKKBN Kabupaten Madiun (Y). Hal ini dikarenakan kemampuan serta latar belakang pendidikan pegawai yang mayorias berasal dari lulusan sarjana. Menurut Gibson (1987), ada 3 faktor yang berpengaruh terhadap kinerja, yaitu faktor individu: kemampuan, ketrampilan, latar belakang keluarga, pengalaman kerja, tingkat sosial dan demografi seseorang, faktor psikologis: persepsi, peran, sikap, kepribadian, motivasi dan kepuasan kerja, dan faktor organisasi: struktur organisasi, desain pekerjaan, kepemimpinan, sistem penghargaan (reward system).

Menurut Anwar Prabu Mangkunegara (2000), kinerja (prestasi kerja) adalah hasil kerja secara kualitas dan kuantitas yang dicapai oleh seseorang pegawai dalam melaksanakan tugasnya sesuai dengan tanggung jawab yang diberikan kepadanya. Kinerja merupakan suatu kondisi yang harus diketahui dan dikonfirmasikan kepada pihak tertentu untuk mengetahui tingkat pencapaian hasil suatu instansi dihubungkan dengan visi yang diemban suatu organisasi atau perusahaan serta mengetahui dampak positif dan negatif dari suatu kebijakan operasional. Mink (2003) mengemukakan pendapatnya bahwa individu yang memiliki kinerja yang tinggi memiliki beberapa karakteristik, yaitu diantaranya: (a) berorientasi pada prestasi, (b) memiliki percaya diri, (c) berpengendalian diri, dan (d) kompetensi.

Namun untuk mewujudkan kinerja yang profesional diperlukan berbagai usaha, salah satunya dengan pengembangan diri pegawai dengan memperhatikan perkembangan teknologi informasi. Pada era globalisasi seperti saat ini, pegawai hendaknya berupaya agar dirinya dapat menguasai teknologi informasi, dengan tujuan dapat mengembangkan kemampuan diri yang nantinya dapat dimanfaatkan untuk pengembangan diri dan organisasi dimana dia bekerja. 
Dari uji Beta, diketahui bahwa variabel yang berpengaruh dominan terhadap Kinerja Pegawai adalah variabel Minat Pemanfaatan Teknologi Informasi (X2) dengan nilai beta sebesar 0,453. Hal ini menunjukkan bahwa menurut para pegawai, dalam meningkatkan Kinerja, pimpinan BKKBN sebagai penentu kebijakan hendaknya memperhatikan cara untuk membangkitkan minat Pemanfaatan Teknologi Informasi.

Nilai $\mathrm{R}^{2}$ (koefisien determinasi) sebesar 0,501 berarti bahwa variasi variabel: Penggunaan Teknologi Informasi (X1) dan Minat Pemanfaatan Teknologi Informasi (X2) memberikan kontribusi perubahan terhadap variabel dependen Kinerja (Y) sebesar 50,1\% dan sisanya sebesar 49,9\% dijelaskan oleh variabel-variabel lain diluar model penelitian. Dari sumbangan sebesar $50,1 \%$ tersebut diharapkan dapat memberikan wacana bagi BKKBN dalam meningkatkan kinerja pegawainya.

\section{KESIMPULAN}

\section{Kesimpulan}

Kesimpulan dari penelitian ini adalah:

a. Terdapat pengaruh secara parsial antara variabel bebas Penggunaan Teknologi Informasi terhadap variabel terikat Kinerja Pegawai BKKBN Kabupaten Madiun.

b. Terdapat pengaruh secara parsial antara variabel bebas Minat Pemanfaatan Teknologi Informasi terhadap variabel terikat Kinerja Pegawai BKKBN Kabupaten Madiun.

\section{Keterbatasan}

Dalam penelitian ini, keterbatasan yang dihadapi peneliti adalah:

a. Sampel yang diteliti terbatas pada pegawai BKKBN Kabupaten Madiun. Pemilihan sampel hendaknya lebih luas sehingga dan variatif sehingga dapat memberikan sumbangsih yang lebih luas dan akurat terhadap penelitian selanjutnya.

b. Peneliti hanya mengangkat dua macam variabel independen yang mempengaruhi kinerja. Peneliti selanjutnya hendaknya meneliti variabel lain di luar variabel yang telah diangkat pada penelitian ini, sehingga dapat memberikan alternatif lain terhadap variabel-variabel yang dapat mempengaruhi kinerja.

\section{DAFTAR PUSTAKA}

Amstrong, Mischael, 1999. Manajemen Sumber Daya Manusia. Terjemahan Sofyan dan Haryanto. PT. Elex Media Komputindo. Jakarta.

A.M, Sudirman, 1990, Interaksi dan Motivasi Belajar Mengajar. Jakarta: Raja Grafindo Persada,

Arikunto, Suharsimi. 2002. Prosedur Penelitian Suatu Pendekatan Praktik, PT. Rhineka Cipta, Jakarta.

Azwar, Syaifudin, 2004. Metode Penelitian, Yogyakarta: Pustaka Pelajar.

Bahri Djumarah, Syaiful, Guru dan Anak Dalam Interaksi Edukatif. Jakarta

Bodnar, G, H., and Hopwood, W.S, 1995, Accounting Information Systems. Prentice Hall, Inc. Engelwood Cliffs, New Jersey. 
Davis, F.D, 1989, “Perceived Usefulness, Perceived Ease of Use, and Acceptance of Information System Tecnology, MIS Quarterly, Vol. 13. No. 3, pp. 319-339.

, Bagozzi, R.P., and Warsaw, P.R., 1989, "User Acceptance of Computer Tecnology: A Comparison of Two Theorical Models", Managemen Science,Vol. 39. No. 8, pp. 983-1003.

Febrian, Jack. 2001. Menggunakan Internet. Bandung:Informatika.

Goodhue, Dale L., 1995, "Understanding User Evaluation of Information Systems",Management Science, Vol. 41 No. 12, Hal. 1827-1844. , 2006, Structural Equation Modeling Metode ALternatif dengan Partial Least Square (PLS), Badan Penerbit Universitas Diponegoro, Semarang.

, Ronald L. Thompson, 1995, "Task-Tecnology Fit and Individual Performance”, MIS Quarterly, Vol. 19. No. 2, Hal 213-236.

H. Djaali. 2007. Psikologi Pendidikan. Jakarta: Bumi Akasara.

Handayani, Rini, 2007, "Analisis Faktor-Faktor Yang Mempengaruhi Minat Pemanfaatan Sistem Informasi dan Penggunaan Sistem Informasi", Simposium Nasional Akuntansi X.

Husein, Fakhri, Muhammad, dan Wibowo, Amin, 2000, Sistem Informasi Manajemen, Badan Penerbit UPP AMP YKPN, Yogyakarta.

Hurlock, B.E. 2003. Psikologi Perkembangan: Suatu Pendekatan Sepanjang Rentang Kehidupan. Ed. 5. Jakarta: Erlangga

Indriantoro, Nur dan Bambang Supomo. 2002. "Metodologi Penelitian Bisnis".BPFE, Yogyakarta.

Jogiyanto, 2007, Sistem Informasi Keperilakuan, Penerbit Andi, Yogyakarta.

Jumaili, Salman, 2005, "Kepercayaan Terhadap Teknologi Sistem Informasi Baru Dalam Evaluasi Kinerja Individual", Simposium Nasional Akuntansi 8, Hal. 722-735.

Jin, Tjhai Fung. 2002. "Analisis Faktor-Faktor yang Mempengaruhi PemanfaatanTeknologi Informasi dan Pengaruh Pemanfaatan Teknologi Informasi Terhadap Kinerja Akuntan Publik". Jurnal Bisnis dan Akuntansi.

Jurnali, Teddy dan Bambang Supomo. 2002. "Pengaruh Faktor Kesesuaian Tugas-Teknologi dan Pemanfaatan TI Terhadap Kinerja Akuntan Publik".JRAI,Vol.5, No.2, Mei 2002.

Kadir, Abdul. 2003. Pengenalan Sistem Informasi. Yogyakarta:Adi Offset.

Kang, Sungmin. 1998. Information Technology Acceptance : Evolving with the Changes

McFarland, L.J., Senn, L.E., and Childess, J.R., 2004, Twenty-First CenturyLeadership: Dialogues with 100 Top Leaders, California: The LeadershipPress.

McKeown, Patrick G., 2001. Information Technology and The Networked Economy, Harcourt: Orlando

Robbins, Stephen P., 1996. Perilaku Organisasi Jilid II, Alih Bahasa Hadayana Pujaatmaka, Jakarta, Prenhalindo.

Sekaran, Uma, 2006, Metodelogi Penelitian Untuk Bisnis, Salemba Empat, Jakarta. 
Singarimbun, M.dan Effendi. 2009. Metode Penelitian Survai, LP3S,Jakarta.

Soekidjo Notoatmodjo, 2003, Pengembangan Sumber Daya Manusia, PT Rineka Cipta, Jakarta

Suprihanto dkk. 2003. Perilaku Organisasional. Sekolah Tinggi Ilmu Ekonomi Yogyakarta: Yogyakarta

Surya, M., 2004, Psikologi Pembelajaran dan Pengajaran, Pustaka Bani. Quraisy, Bandung.

Tampubolon, P. Manahan, 1991, Manajemen Operasional, edisi pertama,. Ghalia Indonesia.

William dan Sawyer. 2003.Using Information Technologi. Yogyakarta:Andi

Warsita, Bambang, 2008. Teknologi Pembelajaran: Landasan dan Aplikasinya. Penerbit Rineka Cipta, Jakarta.

Venkatesh, V., Morris, M. G., Davis, G. B., \& Davis, F. D. (2003). User Acceptance of Information Technology: Toward a Unified View. (C.Beath, Penyunt.) MIS Quarterly 